RESENHAS DE TrRADUÇÃO/ TRANSLATIONS REVIEWS 


\section{SERRA, Ordep. Hinos Órficos: Perfumes. Introdução, tradução, comentário e notas de Ordep Serra. São Paulo: Odysseus Edito- ra, 2015. 768 p.}

Pedro Barbieri

Universidade de São Paulo, São Paulo, SP, Brasil.

Lançada esta tradução dos Hinos órficos, a primeira no Brasil, por Ordep Serra, temos, sem sombra de dúvida, um passo inicial para a divulgação dessa obra algo esquecida nos estudos clássicos lusófonos. O compêndio de 87 hinos acompanhados de um proêmio dedicado a Museu, provavelmente composto entre os sécs. III e IV d.C., vem aqui acompanhado de uma introdução extensa e, no final do volume, diversos comentários interlineares sobre cada hino. Com certeza alguma familiaridade Serra tem com esse corpus, pois, como alega, a largos passos vem trabalhando com os $H O$ (p. 115). Contudo, um problema de seu estudo inicial talvez seja essa mesma familiaridade que, desprovida de rigor, transmite a impressão de certa liberdade excessiva. Serra trabalha com alguns pressupostos duvidosos. Um exemplo aparece já na abertura de seu texto, quando, em meio a

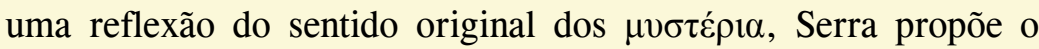
cognato em latim para efetuar a sua leitura, e não o significado do

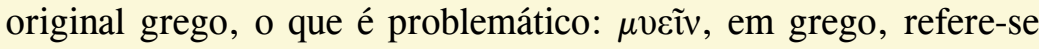
mais especificamente ao ato de cerrar os olhos, não a boca, cujo sentido, por sua vez, só pode ser depreendido do possível cognato

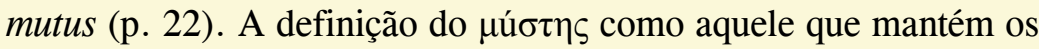
"lábios cerrados", conquanto poética, é algo equivocada, pois deixa contaminar o significado de um cognato a outro. Uma consulta 
ao clássico dicionário de Chantraine (1990) que Serra elenca em sua bibliografia talvez tivesse sanado esse problema.

Outro problema remonta ao próprio título que Serra atribui a essa

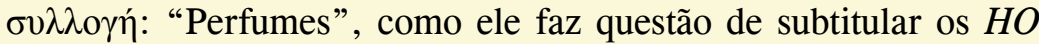
na capa do livro, e ainda "Aromas", que aqui e ali aparecem em seu texto (pp. 31, 33). Trata-se de uma interpretação controversa dos títulos originais, que, em geral, apresentam a fórmula: (nome da divindade no genitivo) $+\theta v \mu i ́ \alpha \mu \alpha+$ nome da oferenda no acusativo. Em um estudo também citado por Serra, A.-F. Morand (2001, pp. 101-52) faz notar a grande presença das oferendas nos títulos levou João Galeno a identificar essa coletânea por suas fumigações. De fato, a crítica francesa aventa a possibilidade da leitura $\theta v \mu i ́ \alpha \mu \alpha+$ nome da divindade no genitivo, do que teríamos, para o décimo hino, por exemplo, algo como "Incenso (ou Perfume) à Natureza", mas logo a descarta reconhecendo que o paralelo dos títulos dos $\mathrm{HO}$ com aqueles dos Papiros mágicos fornece uma forte evidência para como devemos ler a coletânea órfica (pp. 110-1), permitindo a leitura de um genitivo objetivo equivalente a um esperado dativo em línguas românicas. Nessa mesma passagem, o problema da oferenda no acusativo também é tratado e solucionado

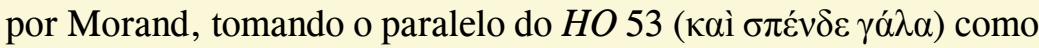
paradigma de leitura e se apoiando ainda na hábil leitura proposta por C. Petersen (1968). Daí temos também a leitura da edição canônica de W. Quandt (1955), que Serra afirma ter consultado (p. 97), mas, que, para continuar no mesmo exemplo, adota a seguinte

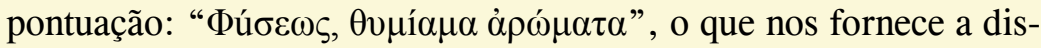
cordância entre o editor e o tradutor. Serra parece, na verdade, seguir a mesma interpretação problemática de G. Ricciardelli (2012) e O. Hatzópoulos (2003), os únicos editores do texto a preferirem a

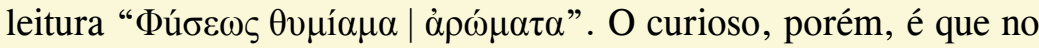
texto grego que consta da tradução de Serra, a formatação se apro-

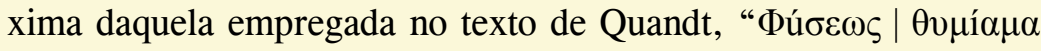
$\alpha \rho \omega \mu \alpha \tau \alpha ”$, do que só é possível imaginar que Serra tenha proposto a seguinte conjectura a seu texto: “ $(\theta v \mu 1 ́ \alpha \mu \alpha) \Phi u ́ \sigma \varepsilon \omega \varsigma, \theta v \mu 1 ́ \alpha \mu \alpha$ 


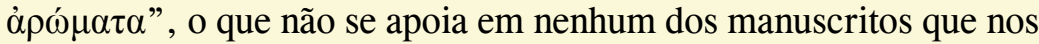
foram legados. Logo: $(\theta v \mu i ́ \alpha \mu \alpha)$ add. Ord. Serra.

O estudo se presta mais a elocubrações sobre a figura de Orfeu, do que um exame detido dos $H O$, o que, por vezes, resulta em conciliações problemáticas de premissas, como o tema do silêncio supracitado, a partir do qual Serra depreende que, no proêmio, Museu se manteria calado enquanto estivesse aprendendo "o rito de sagração" proferido por Orfeu (p. 27). São poucas as páginas destinadas aos HO: entre as pp. 94-101, um descomprometido status quaestionis; entre as pp. 101-12, uma rápida análise da disposição sequencial dos hinos, talvez a parte mais interessante de seu estudo; e, somente às pp. 113-4, uma brevíssima apresentação da estrutura dos hinos, algo que é analisado com muito mais fôlego, por exemplo, em um artigo recente de A. Galjanić (2010). O que se vê com frequência é antes um exercício impressionista do que um estudo propriamente dito. Serra demonstra uma grande dedicação em legimitar aquilo mesmo que ele deveria estar analisando: a atribuição de auctoritas aos $\mathrm{HO}$ por meio da figura de Orfeu.

Compostos e - talvez - performados durante a Antiguidade tardia, é possível que a sua leitura se enriquecesse com um questionamento acerca da forma e do contexto dos hinos, se baseado cuidadosamente em uma abordagem empírica do texto, o que não parece ser o caso. Não temos testemunhos contemporâneos dos $\mathrm{HO}$ e, a não ser que sigamos um $\mathrm{M}$. West, que não se acanha em propor uma imagem bastante nítida da ocasião de performance dessa obra (1983, pp. 28-9), ficamos restritos a um horizonte de observação bastante limitado dos $\mathrm{HO}$ : a própria compilação, da qual é possível entrever indícios textuais de perfomance (cf. Graf, 2009), e, como informação complementar, as correntes ritualísticas do mesmo período dos $H O$. Nesse sentido, uma leitura mais atenta do estudo já mencionado de Morand (pp. 231-87) e ainda de M. H. Jáuregui (2010) poderia ser de grande auxílio. Com efeito, a bibliografia elencada por Serra e o seu manejo dela também é algo debatível. 
Serra faz menção à mais recente coletânea de fragmentos órficos realizada por A. Bernabé (2005), que demonstra claras aprimorações em relação à antiga edição de O. Kern (1972), mas dá preferência a esta última, sem motivo aparente. Do mesmo modo, Serra também faz uso da tradução de 1977 de A. N. Athanassakis, sendo que uma nova edição foi lançada em 2013, agora não só por Athanassakis, mas também por B. Wolkow, com um significante acréscimo de comentários e uma nova introdução. As importantes teorias de A. Dietrich (1891) e de F. Graf (2009), que poderiam em muito enriquecer o seu comentário, apesar de elencadas em sua bibliografia, são citadas en passant no estudo, sem qualquer desenvolvimento. Há um claro descaso pela bibliografia mais atual a respeito do orfismo e dos $\mathrm{HO}$ e, descompassadas como estão, as suas referências só podem gerar um texto opinativo, como é a passagem que versa sobre a sua preferência pela teoria de um Orfeu xamânico (pp. 49-50, 53-5), ou ainda quando trata da influência órfica em Platão (pp. 24-5, 89) - sobre isso, inclusive, o próprio A. Bernabé, autor que Serra usa como argumento a favor de tal influência, conclui que o corpus platônico seria uma "síntese colossal que já não tem nada ou quase nada de órfico” (2011, p. 415). Enfim, um texto opinativo e, portanto, discutível.

Às pp. 112-3, Serra, não obstante fale vagamente da tarefa de tradução dos $H O$, não se detém exatamente sobre a sua tradução, em que ela se apoia e a quem ela se destina. Uma análise de seu texto mostra que em alguns momentos ele parece seguir a escola haroldiana, propondo compostos agramaticais (1.7, "Tomba-Touros"

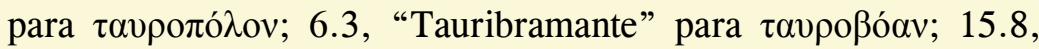

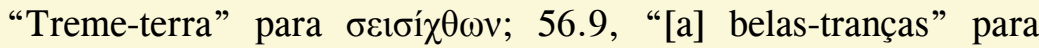

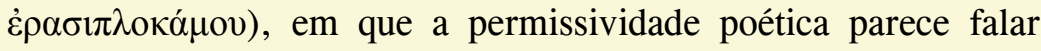
mais alto, além de adotar uma expressividade solene e variegada que destoa da "ladainha", como ele mesmo descreve mais de uma vez, dos originais. Esses dois fatores acabam gerando momentos em sua tradução que não estão presentes nos originais, como o marcante "vinde (...) / ao místico sacrifício e à libação perfeita" 


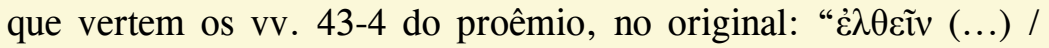

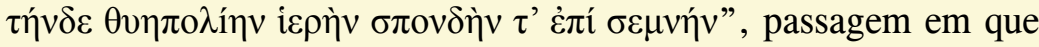
os termos "místico" e "perfeita" dificilmente poderiam ser aceitos e que apresenta uma flagrante tentativa de incutir no texto uma leitura a priori. Dirigida a um público leigo, como me parece, essa tradução acaba, na verdade, justificando uma interpretação comum pela efígie acadêmica, o que não ajuda nem uma parte nem outra.

Trata-se, em suma, de uma edição cujos problemas prejudicam os insights produtivos. Em seu estudo, o cultivo da intuição enfraquece a análise do possível, o que é reforçado pelo aproveitamento precário da bibliografia e por uma tradução controversa. Hinos Órficos: Perfumes supre algumas lacunas, mas dá ensejo a muitas outras.

\section{Referências}

ATHANASSAKIS, A. N. The Orphic Hymns. Missoula, Montana: Scholars Press, 1977.

.; WOLKOW, B. The Orphic Hymns. Baltimore: The Johns Hopkins University Press, 2013.

BERNABÉ, A. Poetae epici Graeci. Testimonia et fragmenta, Pars II. Orphicorum et Orphicis similium testimonia et fragmenta. Munich: Teubner, 2005.

. Platão e o orfismo: Diálogos entre religião e filosofia. Trad. D. G. Xavier. São Paulo: Annablume Clássica, 2011.

CHANTRAINE, P. Dictionnaire Étymologique de la Langue Grecque. Paris: Klinksieck, 1990.

DIETRICH, A. De hymnis orphicis capitula quinque. Marburg: Elwert, 1891. 
GALJANIĆ, A. "Three and then some: Typology of invocation and enumeration in the Orphic Hymns". In: BERNABÉ, A. et alii (Ed.). Orfeo y el orfismo: nuevas perspectivas. Alicante: Biblioteca Virtual Miguel de Cervantes, 2010. p. $122-56$.

GRAF, F. "Serious singing: the Orphic Hymns as religious texts", Kernos 22, p. 169-82, 2009.

HATZÓPOULOS, O. Orphiká, vol. 1. Atenas: Kaktos, 2003

JÁUREGUI, M. H. Orphism and Christianity in Late Antiquity. Trad. J. Ottman e D. Rodriguez. Berlin/New York: De Gruyter, 2010.

KERN, O. Orphicorum Fragmenta. Berlin: Weidmann, 1972.

MORAND, A.-F. Études sur les Hymnes orphiques, Leiden: Brill, 2001.

PETERSEN, C. "Über den Ursprung der unter Orpheus' Namen vorhandenen Hymnen", Philologus 27, p. 385-431, 1968.

QUANDT, W. Orphei Hymni, Berlin: Weidmann, 1955.

RICCIARDELLI, G. Inni Orfici. Milano: Fondazione Lorenzo Valla, Mondadori Editore, 2012.

WEST, M. L. The Orphic Poems. Oxford: Clarendon Press, 1983.

Recebido em: $12 / 05 / 2017$

Aceito em:14 /09/2017 Publicado em janeiro de 2018

Pedro Barbieri. E-mail: pedrobarbieri.antunes@gmail.com 